\title{
The Past, Present, and Future of MOOCs and Their Relevance to Software Engineering
}

\author{
Balakrishnan Dasarathy \\ University of Maryland \\ University College \\ Adelphi, Maryland, USA \\ Balakrishnan.Dasarathy@umuc.edu
}

\author{
Kevin Sullivan \\ University of Virginia \\ Charlottesville, VA, USA \\ sullivan@virginia.edu \\ Adam Porter \\ University of Maryland \\ College Park, Maryland, USA \\ aporter@cs.umd.edu
}

\author{
Douglas C. Schmidt \& \\ Douglas H. Fisher \\ Vanderbilt University \\ Nashville, TN USA \\ schmidt@dre.vanderbilt.edu \\ douglas.h.fisher@vanderbilt.edu
}

\begin{abstract}
Massive open online courses (MOOCs) are a recent development in online education aimed at unlimited participation and open access via the Web. They are a potentially disruptive technology, changing how education is delivered and funded around the world. MOOCs are relevant to software researchers and practitioners, not only because they will increasingly receive lifelong education through MOOCs and related technologies, but also because content creation, delivery, and enhancement of MOOCs is evolving into a new form of socially- and cognitivelyembedded software development.

This paper discusses how education is being enhanced by MOOCs and other digital learning technology. In particular, we distinguish the free educational content provided by MOOCs from the emerging collaborative processes through which MOOCs are created, which is arguably more transformative on education than the content itself. We discuss blended models of higher education to suit different learner communities, as well as nascent moves toward the creation of instructional communities of educators that transcend institutional boundaries. We also explore MOOCs and their evolution as a subject for research in the learning sciences and implications for R\&D in software and systems engineering.
\end{abstract}

\section{Categories and Subject Descriptors}

K.3.1 [Computers and Education] Computer Uses in Education - Collaborative learning, Computer-assisted instruction (CAI), Computer-managed instruction (CMI), Distance learning

\section{General Terms}

Management, Measurement, Performance, Design, Economics, Experimentation, Security, Human Factors.

Permission to make digital or hard copies of all or part of this work for personal or classroom use is granted without fee provided that copies are not made or distributed for profit or commercial advantage and that copies bear this notice and the full citation on the first page. Copyrights for components of this work owned by others than ACM must be honored. Abstracting with credit is permitted. To copy otherwise, or republish, to post on servers or to redistribute to lists, requires prior specific permission and/or a fee. Request permissions from Permissions@acm.org. FOSE'14, May 31-June 07 2014, Hyderabad, India.

Copyright 2014 ACM 978-1-4503-2865-4/14/05...\$15.00. http://dx.doi.org/10.1145/2593882.2593897

\section{Keywords}

Massive open online courses, MOOCs, higher education.

\section{INTRODUCTION}

Software engineering is an incredibly complex business. Every day, successful engineers must draw on broad knowledge, skills, and practices to solve complex problems: including domain knowledge, requirements elicitation, formal methods, design and architecture patterns, human computer interaction, resource management accessibly and usability, programming languages, concurrency and synchronization mechanisms, network and database programming, object-oriented frameworks, security, virtualization, resource management, static analysis, testing, project management and more.

Mastering these areas historically involved physically attending classes at universities that have a critical mass of faculty specializing in these topics. To pass these classes, students must conform to the university's class schedules, course offerings, teaching styles, and pace, which may be inflexible and suboptimal-especially for students who are parents or working adults. Likewise, the rising cost of residential educationparticularly in the USA - is making it prohibitively expensive, even for traditional students [24].

Online education has been successfully addressing many of these problems, especially time and space inflexibility, in many disciplines including software engineering, accounting, and management. A form of online education model is the massive open online course (MOOC), which is a web-based class environment aimed at large-scale global participation and open access via the Web. In contrast to traditional on-campus and established online education, MOOCs enable flexible, open learning styles where students can pick which classes they take, which topics and labs to focus on, which exams to complete, and when and where they do their work. Although much attention has focused on MOOC flexibility and low cost from a student perspective, MOOCs also allow faculty to choose with whom to teach, even spanning institutional boundaries [21].

While MOOCs are still in their infancy, they have already yielded improvements in the production and delivery of highquality digital lecture material, benefitting both online and traditional on-campus courses [25]. MOOCs have also generated considerable interest from research and education communities as 
a focal point for developing and evaluating highly-scalable learning methods and technologies [27].

MOOCs are relevant to software researchers and practitioners for a number of reasons, including the following:

- Software engineering methods and tools are crucial to the development and delivery of effective, customizable, and assessable MOOC-based courses at scale. For example, advances in software technologies are needed to help automate verifiable assessment of non-trivial student assignments, as well as to provide user interfaces and platform that enable students to customize their learning experience based on their backgrounds, interests, and needs.

- Software professionals increasingly receive life-long education via MOOCs and digital learning technologies. For example, many software professionals received their formal education prior to the advent of recent software technologies, such as mobile apps and cloud computing, as well as software engineering methods, such as working in teams across global boundaries and designing and evaluating architectural solutions in terms of reusable pattern and frameworks. MOOCs provide means for these professionals to refresh their skillsets affordably and on their own terms and timeframes.

- The content creation and delivery of MOOCs is evolving into a new form of socially- and cognitively-embedded software development. Software engineering concepts and principles provide key metaphors and methods to help teachers and students frame the development of larger curricular structures, such as MOOC specializations and connectivist MOOCs, as well as relationships between online and in-class components of standalone courses.

Despite the popularity of MOOCs with students worldwide, there's significant debate about their limitations, particularly among higher education faculty, administrators, and trustees. These debates focus on concerns such as (1) unprecedented (unwarranted) hype about MOOCs [19, 11], (2) the deskilling and disintermediation of faculty that compromises education quality and student experience [22], (3) high non-completion rates in MOOC offerings [13, 20], and (4) pressure on institutions to reduce costs, largely in response to massive withdrawal of public funds for higher education [24], and resulting transfer of higher education costs to students and families [33]. The disruptive potential of MOOCs was clear in a recent board-level governance crisis at the University of Virginia [29], a highly respected public university, triggered by a hasty response to articles in the popular press [32] over the threat posed by MOOCs.

To the extent MOOCs might appear to provide a "silver bullet" for financial pressures, some may be tempted to substitute them for courses taught by well trained and professionally paid professors. As this debate has unfolded, several questions have arisen on the role of MOOCs in higher education, including:

- What are the best ways to characterize and understand MOOCs since they don't fit conveniently into established education categories? Section 2 explores key characteristics of MOOCs to help understand and evaluate MOOCs and their future evolution.

- Who are the key MOOC stakeholders? Section 3 analyzes their value propositions, and how their (sometimes competing) interests interact to produce new phenomena over time.

- What are alternative strategies for using MOOCs and digital learning technologies in education? Section 4 examines a spectrum of models for online learning, including those that are neither "massive" nor "open," but which still address the problems of inflexibility in timing and location.

- How will MOOCs evolve in the future? Section 5 examines ways in which the next generation of MOOCs will differ from the first generation of MOOCs offered during the past several years.

This paper presents our assessment of these questions, based on experiences [25] teaching (1) MOOCs via Coursera [26, 25, 17], (2) hybrid courses that blend MOOC content with on-campus lectures [10, 3], and (3) online at the University of Maryland University College (UMUC), the largest public online university [28].

\section{KEY CHARACTERISTICS OF MOOCS}

Although our experience with MOOCs [25, 3] indicates they are a valuable medium for conveying certain types of knowledge, they don't fall neatly into established education categories. To understand the potential and limits of MOOCs, therefore, it helps to draw analogies with earlier forms of media. Although these analogies are imperfect they help us to understand and evaluate MOOCs and their future evolution.

For example, MOOCs can be viewed as multimedia textbooks for Internet-based distance education or as communitybased educational TV shows. Another perspective is that MOOCplatforms will develop into the next stage in learning management systems, both more open and globally accessible. Our view, however, is that MOOCs are content-intensive, socially- and cognitively-embedded, cloud-based computing systems around which communities of content publishers and consumers assemble and interact. In particular, they are more akin to YouTube combined with Wikipedia and Facebook, than they are to traditional books or TV shows. MOOCs are likely to evolve with all these media tools and services, resulting in richer learning and teaching environments.

Although there are various ways to categorize MOOCs, the first generation of MOOCs generally shared the following characteristics:

- $\quad$ They have been delivered to students and the public online openly and freely —often taught (and taken) by professors at top universities around the world. Some MOOCs provide open access to course content, which helps promote reuse and repackaging of material for other faculty. Other MOOCs don't permit reuse of the material without permission, though students can still access the material freely.

- MOOCs are offered as standalone courses, rather than part of an organized curriculum. In contrast, conventional oncampus courses follow well-defined sequences to ensure that students have the necessary background knowledge and experience before attempting to learn the new material.

Various consequences flow from these characteristics. For example, the completion rate of MOOCs is low: typically only 5$10 \%$ of MOOC registrants actually complete the course. In 
contrast, completion rates at the University of Maryland University College (UMUC) —an established online programare greater than $50 \%$ at the graduate level after the second semester of enrollment (and would be higher if UMUC had a more selective admission policy). Completion is greater than $85 \%$ at selective residential universities, such as Vanderbilt and the University of Virginia. There are various explanations for low completion rates in MOOCs [13]. For example, because MOOCs have no prerequisites and are free, many students aren't adequately prepared to master the material or aren't motivated to finish the entire MOOC since there's no penalty for noncompletion.

Judging from analyses of the completion rates, MOOCs offered to date appear better suited for highly self-motivated learners than those less self-motivated (who may benefit more from conventional residential education models [20)]. First generation MOOCs tend to couple text and video material that can be browsed separately from other course material, such as assignments and exams. Students often find value in these text and videos, and feel no need to participate in all the trappings of the full course format. In this sense, MOOCs are used like books, where students can learn a lot without necessarily reading every page, cover-to-cover, in printed order. A significant fraction of non-completers may simply benefit as they would by sitting with a book in a library or at home: picking, choosing, with no sense of obligation to report to anyone or to be assessed. In this view, students are "active auditors" who use MOOCs like streaming, on-demand, educational TV shows, delivered by inspiring teachers.

Another consequence of first generation MOOCs is that they aren't well-suited for fields (such as Chemistry and Biology) with labs that require preparation, experimentation, specialized equipment, observation, and result capture. Likewise, it's hard to assess massive numbers of sophisticated assignments accurately in first-generation MOOCs due to limitations with the current stateof-the-practice of auto-grading and peer-grading methods and tools [25]. These limitations may be ameliorated over time as research on state-of-the-art automated tools and methods transition into practice [11] and as MOOCs incorporate capabilities for online laboratories found in other online learning contexts [23]. In general, however, drills, exercises, and interpersonal interactions don't yet scale in the same way as lecture delivery via current MOOC platforms.

\section{MOOC STAKEHOLDERS AND VALUE PROPOSITIONS}

Another way to think about the evolution of MOOCs is in terms of stakeholders in the MOOC ecosystem and their value propositions. Stakeholders include (1) MOOC content publishers and curators, (2) professors, (3) universities, (4) traditional and non-traditional students and their families, (5) the public, and (6) scholarly communities. This section develops this perspective.

\subsection{Key MOOC Stakeholders}

Popular MOOC publishers and curators (e.g., Coursera, Udacity, EdX, and others) currently provide courses for free, but are ultimately profit-driven enterprises. Their chief value proposition is eventual financial profitability and wealth creation for their investors and owners. One reason why content publishers engage in the MOOC market stems from the enormous amounts of money spent on education, at all levels, each year.
For example, Americans spent about $\$ 461$ billion for postsecondary education in $2009,42 \%$ more than the amount spent in 2000 [5]. These costs are becoming prohibitive in many countries; e.g., it can cost over $\$ 50,000$ a year to attend a selective private college in the USA. The content publishers and curators perceive that MOOCs can help (1) universities, by reducing some of their operating costs, (2) students and their families, by making education more affordable, better, and accessible [24], (3) and future employers of students, by providing data on student performance and credentials in designated areas of study.

Professors have several value propositions. Faculty can benefit by folding MOOC content into their own courses via blended learning [3] and flipped classroom methods [10]. Such use involves learning MOOC content quickly enough, as needed, to teach new material themselves and/or adapt the online content directly into their own courses. Opportunities to get up to speed more quickly and to incorporate free, high-quality material into classes have real value for professors. Likewise, MOOCs and online content generally enable instructional communities of educators to create and share content readily, on platforms ranging from Coursera and EdX, to YouTube.

Coursera, Udacity, and EdX have also created an impressively successful-albeit only quietly recognized - "star professor" award system that helps MOOC faculty burnish their personal brands. For example, faculty invited to produce and deliver MOOCs receive acclaim and visibility, which are coins of the realm in academia. Faculty who teach MOOCs may also find numerous ways to monetize their fame, for example, through speaking engagements, by teaching with for-profit content publishers, such as Pearson's LiveLessons video series, aimed at corporate training, and more.

Universities are major stakeholders. They value their own financial health, which makes them sensitive to educational costs and quality. They value their students and the student experience. They also greatly value their reputations, on which student demand and tuition revenues depend. In part for this reason, in conventional MOOC models (such as Coursera and EdX), universities play a vital role as arbiters of what MOOC content gets produced and delivered by their faculty.

Traditional and non/traditional students are stakeholders, both as consumers of the MOOC content and as potentially scalable labor pools for peer assessments and crowd-sourced content review and improvement. Likewise, families/employers are stakeholders to the extent that their loved ones/employees education will be enhanced (or not) by MOOC-related changes in education, or by the impact of MOOCs on higher education costs. Ironically, families paying the tuition of their children who attend top universities may be indirectly funding MOOCs (the so called "MOOC tax") since the costs of the faculty and staff who produce and deliver MOOCs may be paid from the tuition charged to residential students and their families.

The availability of MOOC materials is a boon to people around the world. In some cases for the first time, people around the world have opportunities to access the materials and processes of quality higher education.

While MOOCs have initially focused on individual courses that are closely related to traditional on-campus coursesMOOCs in-the-small-there are opportunities for MOOCs in-thelarge, as well, where coalitions or communities of scholars 
document whole bodies of knowledge in MOOC-like form. This possibility raises questions regarding the architecture of knowledge and the means for its large-scale production and evolution.

\subsection{Implications of this Value-Proposition Analysis}

There are a number of implications of our value-proposition analysis presented above.

MOOC content publishers must become profitable, evolve into something different, or go out of business. Current MOOC providers, such as Coursera, EdX, and Udacity, are multimedia publishers (who focus on content creation, integration, and dissemination), rather than higher education institutions (who focus on scholarship, assessment, and credentialing). These providers are in the same market as companies like Pearson, i.e., publishers seeking to develop and promulgate new educational uses of the Web and related technologies, such as mobile devices, cloud computing, and data analytics.

These publishers have so far operated with investors' capital, but their business models will have to become sustainable soon. As they do, there will be changes in the tradeoffs involved in collaborating with these publishers, as seen by other university, faculty, and student stakeholders. These providers may also find themselves threatened by rapidly falling barriers to entry into the MOOC market. For example, the availability of the EdX MOOC platform (mooc.org) coupled with consumer-priced video production tools (e.g., cameras, audio, light, green screens, teleprompters, screen capture, editing software, and video hosting) makes it relatively easy and cheap to produce content of satisfactory quality.

Thus, even smaller players may be able to undercut the big MOOC publishers and commercial course management platforms. As production costs decrease it's possible that we will see a decentralization of MOOC creation, and broader adoption of open-source alternatives to proprietary MOOC publishers and platforms. A distinct (but not disjoint) possibility is that MOOC companies may position themselves as independent institutions of higher education-not a college but a "collage”, using content from other sources and giving badges, other credentials, and even degrees.

Universities need to become savvier about providing private enterprises valuable intellectual property, as well as the data produced by student engagement with these interactive systems. The value exchanges need to make sense financially and respect pedagogical goals, privacy, and legal and ethical obligations to students. If universities choose to implement their own MOOC platforms, it may become feasible to move production in-house and to control distribution. To the extent that Universities own course content, pressures will militate against unlimited free distribution. As with newspapers like the New York Times, universities will struggle to balance financial self-interest against the public good and other stakeholders' interests.

If universities focus on the parts of education that are not easily delivered online they may treat MOOCs as simply another service they can use to further their educational missions and outreach. Examples include individualized face-to-face instruction, exposure to cutting edge facilities and research projects, access to study abroad programs and internships, and integrated learning opportunities that span diverse learning fields.

The benefits that professors have garnered from being MOOC stars will fade as barriers to entry and novelty diminish. Professors may also decide the benefits of creating MOOCs are outweighed by the costs in time and lost opportunities. Of course, a small number of popular star professors could be backed by investors with resources that neither individual faculty nor institutions could provide. It's also possible that actors will eventually play professors, to deliver content with professionally trained voices, familiar faces, and acting skills. While some institutions, and even professors, hire professional filmmakers to produce their MOOCs, high production values aren't always necessary if the content is useful to consumers, as Kahn Academy has shown.

Access to free, high-quality educational materials is positive for students. A MOOC can be of enormous value by providing access to materials that might otherwise be inaccessible. High quality MOOC courses will also pressure all professors to up their game, as students and their families raise their expectations based on exposure to professionally produced MOOCs.

A key question is whether in the long run students will be disadvantaged if educational institutions try to teach MOOC content using low-cost teaching assistants to replace classes traditionally taught by professors. In this regard, the question isn't necessarily whether MOOCs are as good as traditional on-campus courses, but whether they are so much cheaper that businessoriented governing boards and legislatures will see them (with or without adequate rationale) as good enough to justify sweeping changes. Something valuable for students and society may be lost if students can no longer experience the benefits of education and mentoring by committed, physically present, highly qualifiedand often inspiring-professors.

It's not yet clear, however, that thoughtful university leaders see acceptable ways to use MOOCs to reduce costs substantially in the short term. For example, just as existing instructional content represents an enormous investment, MOOCs are costly to produce (often thousands of dollars per hour of finished material). Moreover, interaction, feedback, testing, and creating a learning culture are all labor- and knowledge-intensive and do not (yet) scale as well as lecture delivery (which is only one part of teaching). For now, top institutions are using MOOCs to increase their students' "bang for the buck" (i.e., increasing "the bang," not reducing "the buck") by creating or reusing MOOC offerings, in addition to providing all the richness of traditional courses, as discussed in [10, 3] and explored further in Section 4.2. Others are incrementally creating MOOCs, adding content bit-by-bit over a long period of time, and integrating this new material with traditional lectures as parts of flipped classrooms.

Visibility into the materials and processes of higher education is wonderful for the broad public around the world. Making high-quality course materials freely available is an enormous contribution to the public good. Universities and professors need to decide, however, whether they'll remain committed to this goal given the costs and need for sustainable business models. It's not clear that we'll see a continued proliferation of high quality open MOOCs, due to the lack of a clearly articulated return on investment. We may see MOOCs used as "loss leaders" for profitable online degree programs, i.e., 
as a natural specialization of a strategy that uses MOOCs for branding, recruiting, and outreach.

Communities of knowledge are also likely to recognize the potential of MOOC-like encodings of knowledge. Professional, societies (such as the IEEE) have historically documented bodies of knowledge (e.g., the Software Engineering Body of Knowledge available at www.swebok.org). A carefully architected set of MOOC-like courses may be a viable-and potentially far more useful and accessible-representation of the stable knowledge of a field, such as computing or software.

As stakeholders begin to understand and adapt to this ecosystem - and as technology and teaching methods maturefirst generation MOOCs will likely be replaced by more evolved tools and methods that computationally enhance education, including methods for better organizing the bodies of knowledge in many fields into more readily accessible digital form

\section{ALTERNATIVE STRATEGIES FOR USING MOOCS}

This section describes our vision of how the digital learning capabilities_-leveraged and promoted by MOOCs_are evolving in higher education based on our experience. In our view, there's no one-size-fits-all model for digital learning. Instead, we expect that MOOCs, SPOCs (small private online classes) [11], and traditional residential education will blend together to support different types of students in different academic and work situations, as shown in Figure 1. The continuum in this figure depicts different digital learning adoption strategies ranging from traditional residential education (which is largely synchronous and delivered face-to-face) to online education programs (which are largely asynchronous).

\subsection{Evaluation Criteria for Digital Learning Models}

To understand how digital learning is evolving, we first assess what attributes a particular learning model supports. The following attributes provide a basis for understanding and evaluating various learning models:

- Quality of realtime feedback and motivation - How well (and soon) do teachers/learners assess and provide feedback to alter directions or missteps?

- Learner accountability - Are students who they say they are and is their work original?

- Curricular diversity and depth - How broadly and deeply are disciplines covered?

- Well-roundedness - Education is more than a mastery of content; does the model support learning soft skills, including social, and leadership skills?

- $\quad$ Support structures - How effectively are students guided and mentored when questions and difficulties arise in academic and non-academic aspects of real or virtual campus life?

- Scalability - How well does the model support increasing the number of learners without having detrimental effect on the quality of learning?

- $\quad$ Cost - Does the model support affordability by learners (and their parents, employers, and taxpayers), i.e., are the benefits worth the cost?
- Flexibility -How free are students to choose the time place and path of their learning?

- Accessibility - To what degree are educational resources available to physically-challenged learners.

- Diversity -Does the model support diversity in socioeconomic, cultural, and geographic dimensions?

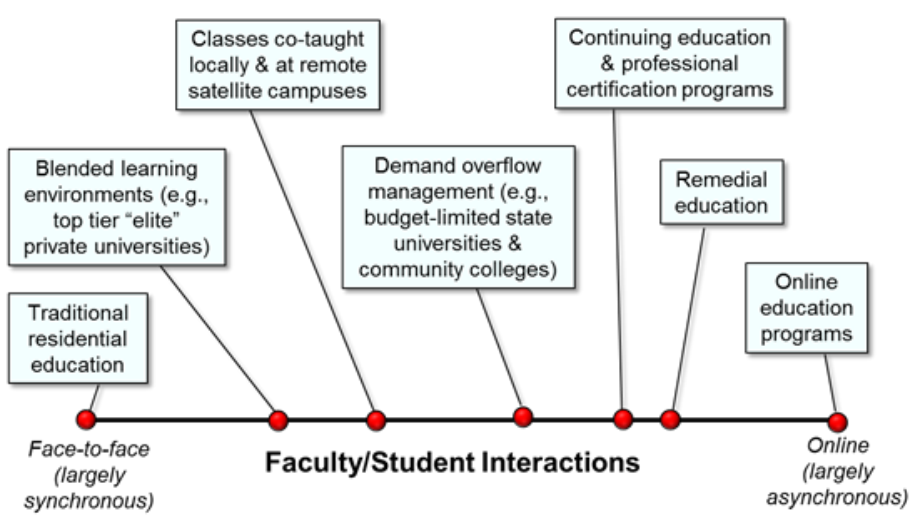

Figure 1: Strategies for Digital Learning Adoption

\subsection{Alternate Digital Learning Adoption Strategies}

Below we use the attributes described above to characterize and evaluate models across the spectrum shown in Figure 1. Likewise, Table 1 (at end of paper, after references) applies the assessment criteria presented above to compare and contrast the following two models at opposite ends of this spectrum:

- Traditional residential education. In its idealized (and sometimes romanticized) form, this model is characterized by an immersive education experience that places a premium on frequent, in-depth, and synchronous face-to-face interactions between faculty and students. Universities are communities that cater to many aspects of student scholastic and inter/intra-personal development, including sports and recreation, social engagement, political activism, student organizations and clubs. Although the residential education model has a long and successful history, it's also expensive. For example, during the past several decades tuition costs in the USA have risen much faster than the rate of inflation-especially as public support for institutions of higher education has been radically reduced-increasing U.S. student debt above \$1 trillion [33].

- Online education programs. This model is characterized by working professionals interested in advancing their careers or entering new fields. These programs typically offer careeroriented degrees and professional certificates in accounting, finance, management, IT, cyber security, etc. Students are generally adult learners who are not looking for social and networking skills and opportunities. Unlike MOOCs, online class sizes are typically small to personalize learning experiences. There's a potential to leverage MOOCdeveloped lectures in this model to reduce costs, especially in core courses. Conversely, Udacity is focusing on making inroads into higher education not with MOOC-developed content, but with technology and support services for this online education market for credit at traditional universities 
[16]. There's a need to leverage authentication and identification biometric techniques to minimize impersonation which helps improve the credibility of online degrees [1].

As discussed in Section 2, MOOCs can be viewed as a microcosm of digital learning, so they share many characteristics of the online education model outlined in Table 1. MOOCs can scale better (at least the delivery part) and may even be cheaper and more diverse than traditional online education models. First generation MOOCs, however, perform poorly on the first five rows of attributes listed in Table 1, even more so than traditional online education model due to their massive size.

While the two models evaluated in Table 1 are stereotypic education models-albeit at opposite ends of the spectrumhybrid approaches are also becoming popular. For example, residential education institutions are adopting technologies and concepts (such as flipped classroom) that leverage MOOCs without going fully online. Likewise, online education programs may require some face-to-face interactions with students (e.g., to authentic their identities in a physical testing center). The remainder of this section discusses ways in which different strategies for adopting digital learning (all of which both leverage and inform MOOCs to some extent) can yield different blends of synchronous and asynchronous models of faculty/student interaction:

- Tightly-coupled blended learning environments. This hybrid model is being explored and adopted in top-tier institutions [10, 3]. The main goal is not cost reduction, but increasing teaching effectiveness by leveraging multimedia content (including content from MOOCs taught by faculty at other universities), innovative student/faculty engagement methods (such as flipped classrooms), and online discussion forums (such as Piazza) that encourage asynchronous interactions between faculty, course staff, and students. For example, all Vanderbilt faculty who have offered Coursera MOOCs are applying the material from their MOOCs to augment their on-campus classes. Likewise, two of the authors of this paper, Adam Porter and Doug Schmidt, developed course content first for on-campus flipped classroom courses and then transitioned the material to a Coursera MOOC specialization (a set of courses organized around a particular topic). A key benefit of the blending learning model is increased flexibility in faculty-student and student-student interactions; other attributes of this model are essentially the same as traditional residential education.

- Classes co-taught locally and via remote satellite classes. In this hybrid model local classes are taught face-to-face and lectures are broadcast using streaming media to remote campuses. Remote campus classes are largely staffed by adjuncts and/or junior faculty. The course delivery to satellite campuses is predominately synchronous. Concepts such as flipped classroom and asynchronous discussion sessions from MOOC can be applied to enhance learning/teaching effectiveness. One benefit of this model is that virtual communities can form within and across campuses due to digital learning technologies.

- Demand-overflow management. In this hybrid model some courses are offered online and some face-to-face. Students will live in traditional residential settings, taking some classes on-campus-especially in fields that require labs and/or mentorship and/or collaborative work (such as capstone design courses). Other classes (e.g., general education courses) will be conducted entirely online. Cost is a key consideration, though curricular diversity and well roundedness are also considerations. We expect many state universities will consider adopting this model (e.g., California is an early adopter [2]) since they are obligated to educate large numbers of students, despite cuts in funding from their legislatures. We also expect intra-state consolidation for online courses and leveraging content from MOOC for both online and face-to-face classes [15]. With the right blend of courses - and the proper attention to pedagogy, mentoring, and assessment-students may get the best of both online and face-to-face class experiences, although not necessarily at the same time.

- Continuing education and professional certification programs online. In this hybrid model students are typically working professionals. Often, they received their undergraduate degree at the same university in residential setting, which provided them with opportunities for networking and acquiring social skills. Continuing education programs are often short duration (e.g., several day "short courses”), whereas professional certificate program may last longer (e.g., multiple semesters). These models may also be ideal for Professional Master's programs in areas such as software engineering, accounting, and project management. The MOOC platform technology will be competing here with other established learning management platforms, such as Blackboard and Desire2Learn. This model could also support hybrid classes where most class sessions are delivered online, but students must attend face-to-face-sessions periodically (e.g., every other Saturday or for a several-month residency period) or take exams in person. Authentication and identity issues may be less of a concern in this learning model than in a typical online university since the students spend face-time with their instructors on a regular basis.

- $\quad$ Remedial education. In this hybrid model only remedial courses are delivered online. Many state universities are obligated to admit students that graduated from their own state's high schools; state schools will be more amenable to offering remedial courses online to reduce the failure rate and education costs. Students may choose only to audit the course. This model largely preserves the traditional oncampus degree. Social media (such as YouTube and Wikis) and MOOCs may play a role here since remedial courses have a broad market, especially in areas such as mathematics, introductory programming, computer literacy, and English as a second language. For-profit institutions may also contribute free remedial education materials to enhance their appeal.

The blended models covered above are neither mutually-exclusive nor are they exhaustive. We envision these blended models moving increasingly into K-12 education (perhaps replacing or augmenting "Advanced Placement” exams), and into community college education, as well as changing the content provided in a multi-year residential university experience.

\section{THE FUTURE DIRECTIONS OF MOOCS}

This section summarizes some of our views on how future MOOCs will differ from the first generation of MOOCs. 


\subsection{The Growing MOOC Landscape}

As institutions continue to produce and host MOOCs, rich curricular possibilities are going online. As early as Fall 2012, the entirety of what many would regard as the computer science curriculum was online and freely available. Figure 2 shows a small part of this larger curriculum - the introductory courses from several prestigious schools as MOOC offerings - and a path that a student could take through a small part of this space of courses. As students piece together their paths through the MOOC space, they are customizing a curriculum. In the near term we expect that crowd-sourcing will lead to consensus favorites, as some paths (i.e., customized curricula) are endorsed more than others. The embedding of MOOCs and MOOC platforms within social networks will accelerate this activity. Moreover, as software emerges to organize, preserve, and demonstrate the portfolio of knowledge students acquire through MOOCs, new ways of certifying academic achievement will become common and acceptable. While the idea of a customized and crowd-sourced, multi-institution curricula may start with computer science and software engineering, it can also generalize to other disciplines.

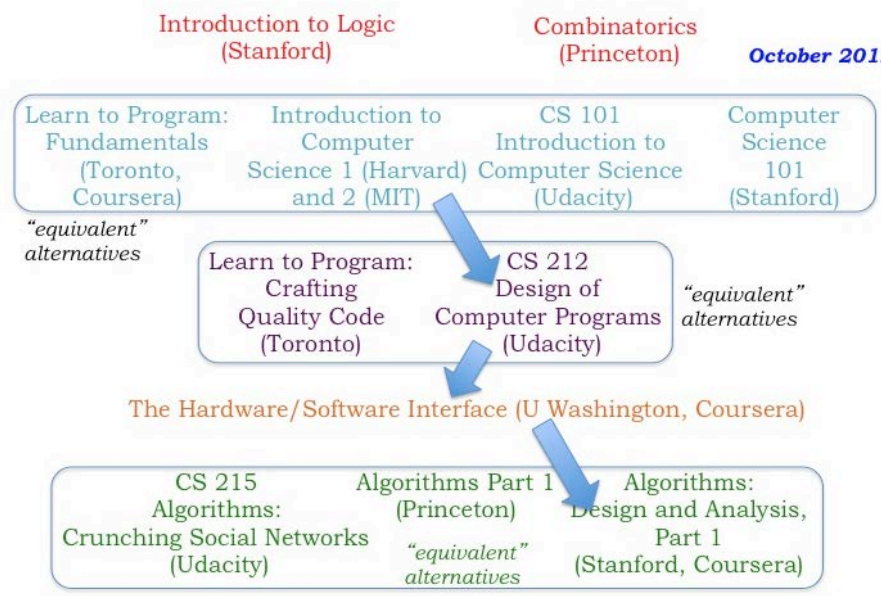

Figure 2: Customizing a Curriculum Path

These open curricular possibilities have emerged through a loose coupling between institutions and faculty, with curricular structures across MOOCs being inherited from the traditional curricula that have evolved over many generations. Institutions are only just now recognizing that more proactive and deliberative collaborative processes of curricular design are possible, as discussed in Section 5.4.

\subsection{The Emergence of "MOOC-as-Process" to Complement and Extend "MOOC-as-Thing"}

The first generation of MOOCs has mostly been perceived mostly as things, such as "digital textbooks" or "educational TV shows," as discussed in Section 2. These MOOCs are usually created as a series of videos and associated digital content by a single "star" instructor and broadcast to a grateful world. Our experience, however, indicates that MOOCs are not merely things, but also processes, e.g., processes of design and production, processes of consumption (use, and the kinds of communities that develop around individual course offerings), processes of evolution, and (perhaps most significantly) processes of collaboration.
Viewing MOOCs also as processes is more enlightening than just viewing them as things since it highlights the pedagogical methods that are enabling the evolution of higher education from individual instructors working largely in isolation with their (relatively few) face-to-face students to much larger virtual/global communities of faculty/students who share common teaching and learning philosophies, interests, and background knowledge.

This process view also decomposes and differentiates the fast dynamics of individual course offerings from the slower dynamics of MOOC development and evolution. As MOOCs scale up to capture broader fields of knowledge systematically, this view becomes more interesting and more akin to large-scale development of cyber-social soft-ware systems, as discussed in Section 5.5.

As the stakeholders we analyzed in Section 3 gain greater experience with MOOCs, the new pedagogical methods enabled by digital learning technologies, in general, and MOOCs, in particular, will become more transformative. For example, these methods will provide students and teachers with greater control over the time, place, path, and pace of learning. They will also significantly impact how education is created, packaged, delivered, assessed, and priced.

Ultimately, it's the process dimension of MOOCs (and more generally, digital learning methods, tools, and philosophies) that will have the greatest impact on higher education, as faculty and students start proactively designing and implementing transinstitution curricular structures, such as those discussed in Sections 5.3 and 5.4. The "MOOCs-as-things" metaphor that's predominant in the first generation of MOOCs is just a precursor to promising changes in teaching and learning stemming from the collaborative and creative processes enabled by MOOC platforms, digital learning processes, and virtual instructional communities.

\subsection{An Open-Source Educational Environment}

Digital learning technologies (initially manifested by-but ultimately transcending-first-generation MOOCs) will enable collaborative teaching and learning in a manner and at a scale that hasn't been feasible before. A relevant analogy is the way in which the Internet/Web has enabled virtual communities of experts (and those aspiring to become experts) to collaborate effectively on sophisticated open-source software development projects (such as Linux, Apache, GNU, ACE+TAO). Prior to the creation of this powerful digital infrastructure, software developers tended to collaborate mostly face-to-face with colleagues from their same organization. Digital technology changed all that, even though at first many developers viewed the Internet/Web only as a means to access documents remotely or to communicate asynchronously with their colleagues via email.

As the Internet/Web matured, however, and new generations of distributed development tools (e.g., SVN, GitHub, SourceForge, Bugzilla, Hudson, etc.) and communication tools (e.g., IRC, WebDAV, Wikis, YouTube, WebEx, etc.) emerged and were adopted, the real transformative nature of this new digital infrastructure became clear. Today, virtual collaborations among a wide range of software development communities span time zoness and organizational boundaries, support diverse business models, and have radically changed how software is developed, tested, and evolved. The key lesson here is that digital infrastructure was transformative because it enabled new, more 
powerful forms of collaboration, not simply because it allowed developers to access content more flexibly. Likewise, MOOCs are enabling collaborations that were not feasible before.

In the future, MOOCs will increasingly support trans-institution, sequenced learning engagements that flexibly assemble communities of teachers and students from around the world who share a common educational philosophy and who have complementary interests and expertise on a range of relevant topics. These new forms of MOOCs will foster collaborations among teachers and students that span traditional inter- and intrainstitution and disciplinary boundaries - and thus provide a more seamless continuum of education to students, as discussed next.

\subsection{Sequencing MOOCs by Design: Encouraging Community-Based Instructional Collaborations}

Online education programs traditionally stick close to the structure of their on-campus antecedents. We envision that many MOOCs will emerge-sometimes opportunistically, sometimes intentionally-within and across institutions to fill in various slots of traditional disciplinary curricula, as discussed in Section 5.1 and shown in Figure 2. Within each of these largely standard areas of study, sequencing of MOOCs by students interested in curriculum-level learning will naturally follow traditional course structures. We also envision that formal recognition for study of a field will emerge, ranging from badges to diplomas, with courses that span institutions.

As we get to advanced courses, however, the well-trodden curricular paths are less obvious, and intentional sequencing MOOCs by design becomes more important. Vanderbilt and University of Maryland have recently taken the lead in moving beyond opportunistic MOOC path-finding. In particular, Adam Porter from the University of Maryland has joined together with Doug Schmidt and Jules White of Vanderbilt to design and delivery a trans-institution sequence of MOOCs offered as one of the first specializations on the Coursera platform [17].

This Coursera specialization focuses on "Mobile Cloud Computing with Android” (MoCCA) and integrates content that is not currently taught as a unit in either institution. The first MOOC in the MoCCA specialization-the University of Maryland's course Programming Mobile Applications for Android Handheld Systems taught by Adam Porter-focuses on design and implementation of user-facing applications. This MOOC covers the fundamental programming principles, software architecture, and user experience considerations underlying handheld software apps and the Android development environment.

The first Vanderbilt University MOOC offered in the MoCCA specialization-Programming Mobile Services for Android Handheld Systems taught by Doug Schmidt-builds upon the material covered in Porter's MOOC and focuses on middleware systems programming topics, such as synchronous and asynchronous concurrency models, background service processing, structured data management, and local inter-process communication and networking. The second Vanderbilt MOOC in the MoCCA specialization-Programming Cloud Services for Android Handheld Systems taught by Jules White-focuses on how to connect the mobile device software covered in the previous MOOCs together with cloud computing and data storage resources, turning a mobile device into an extension of powerful cloud-based services.
Although this MOOC specialization has just begun (Porter's MOOC started in January 2014 and Schmidt and White's MOOCs start in May and July 2014, respectively), our experience thus far indicates MOOC-style teaching or technologies developed for MOOC will beneficially impact software engineering education including the following:

Integrative learning models. Software professionals increasingly need to assemble many components developed by themselves and others to form complete systems. These types of integrative concepts and skills are often neglected in traditional universities, which don't have adequate time in their curricula to have students combine a group of related technologies and components into complex solutions.

To integrate the material covered in all MOOCs, therefore, a coordinated set of assignments is employed throughout the MoCCA specialization. For example, students taking Porter's course will build the user-facing portions of a mobile app using server modules provided by Schmidt and White. Students in Schmidt and White's courses will build the server portions of the app using client modules provided by Porter. The end result will be a complete end-to-end app that demonstrates the patternoriented integration of Android mobile devices with cloud computing platforms.

Hybrid assessment mechanisms. Assessing student performance in the software engineering courses we teach at our universities involves a significant amount of manual scrutiny. For example, we typically review the software written by our students. While that level of personalized scrutiny works for a small class, we can't afford to assess the solutions from our MOOC students (the first MOOC in the MoCCA specialization has more than 200,000 students enrolled!).

Ideally, scaling up POSA MOOC assessments would apply autograding tools. Despite being an active field of research, however, the auto-grading tools available to assess students in designoriented MOOCs (such as MoCCA) aren't as mature as in "factbased" MOOCs (such as Algebra or Pre-Calculus). The problem stems from the lack of tools for auto-grading software designs in terms of (relatively subjective) quality attributes, such as reusability, understandability, and evolvability.

To address this issue in the MoCCA specialization we're adopting a hybrid assessment model where we first apply auto-graders based on the Android Robotium test automation framework, which we use to write black-box function, system and acceptance test scenarios, spanning multiple Android activities. These autograders are then supplemented with calibrated peer-graded assessments, which employ a web interface supplied by Coursera to guide students through a grading rubric and score each submission and enter free-form comments.

Virtual globally distributed team projects. The final course in the MoCCA specialization is a joint capstone project offered to students who successfully master the material covered in the earlier MOOCs. In this project course, instructors from University of Maryland and Vanderbilt University will help students apply all that they learned before to develop a complete mobile cloud computing application from the ground up. Students will self-assemble into teams and work remotely using distributed development tools (such as GitHub, SourceForge, Bugzilla, and CruiseControl) and communication tools (such as Wikis, YouTube, and Skype). 


\subsection{Competency-Based Learning}

Digital learning environments are facilitating multi-institution curricula and flexible paths to degrees. Evaluation of courses from other institutions, and administrating tests to award credits, will thus play an ever-increasing role in many of the schools that specialize in career or professional education.

The role of an academic advisor will grow to include stitching together a degree program from multiple institutions to meet student needs (e.g., cost, location and geographic diversity, and mode of interactions). Moreover, this academic/curriculum advisor might not be affiliated with any one institution.

Moreover, MOOCs and other forms of digital learning will increasingly attract non-traditional students (such as working professionals) who often already have some knowledge of a given field. These students will typically want to avoid the time and expenses associated with taking courses that cover information they already know. Opportunities therefore exist for institutions to test or evaluate prior knowledge for credit.

In this context, competency-based education [9, 12] and assessment of competency will increasingly be the means by which schools will distinguish themselves. Competency-based education is gaining traction in private and public and both in online and face-to-face institutions [30, 4, 8]. Competency-based education is not just about prior knowledge, but more about ability to apply knowledge or more generally ability to do a job function.

Most institutions currently give credit to courses from other institutions in an informal and ad hoc basis (two or three in the administration and relevant academic departments will only need to sign off for credit transfer). As pressure mounts to award credit for competencies gained at work, MOOCs, etc., this process should become more rigorous, e.g., based on tests, labs, miniproject assignment, etc. The results of this type of formal evaluation for a given set of students prior to entering a course can also better enable faculty members to tailor their course content and delivery.

Although competency-based education might lead to decreased enrollment in certain courses (e.g., due to more students "placing out") this revenue might be supplanted in testing and evaluation. Likewise, competency-based education could attract more learners to institutions, which would yield a win-win situation.

Working with government and professional groups, educational institutions will be and need to be developing competencies. For example, the Department of Homeland Security, with input from universities and industries, is currently developing competencies for cyber security education [7].

MOOCs are attracting learners who do not aspire to a degree, completion certificate, etc., but who are just interested in doing their job better with the knowledge gained in a MOOC course [6]. What attracts these learners are the very aspects that are associated with MOOCs' low completion rate, such as no regular attendance, limited testing/grades, no stigma of dropping out, and, of course, no tuition fees. From this perspective, MOOCs are a step forward in the competency-based education arena. One question a MOOC course designer should therefore ask is "what competencies am I trying to facilitate?," which is a learner-centric approach to education.

\subsection{MOOCs as Cyber-Social Software Systems}

In Section 5.2 we argued that MOOCs are not just things, but are also processes. Elaborating further, MOOCs embody (at least) the following intertwined processes:

- MOOC development - This process generally involves faculty, experts in multimedia content production, pedagogical interaction designers (often faculty themselves), and information technology platform-based implementation experts.

- $\quad$ MOOC enactment - This process involves the delivery of the course as a long-running, interactive computer system or "program," serving multiple classes of users, including students, faculty, teaching assistants, and system support staff.

- MOOC consumption - This process involves students learning the material delivered during MOOC enactment, as well as increasingly producing new content (or refining existing content) as a response to difficulties they encounter as consumers.

Viewed this way, MOOCs and the learning processes they embody are cyber-social ecosystems, in which communities of human minds are coordinated and enhanced in organized and measurable ways with the support of underlying, and evolving, digital infrastructure systems.

This “MOOC-as-software” perspective captures Gregor Kiczales's notion that MOOCs are different from traditional books, because they are more malleable [14]. As Kiczales observes, MOOCs can be revised in an agile and ongoing manner, whereas with traditional (i.e., non-electronic) books, few changes other than error corrections can be made after a book is in print (short of new editions, which are costly and infrequent).

This property of malleability is familiar to every software engineer and computer scientist. It is one of the essential properties of software, i.e., it is the "soft" in software. It's also where much of the value of software lies, which makes phenomena of software evolution deeply important. A crucial objective for the next generation of MOOC technology will thus be to enhance the softness/malleability of MOOCs, allowing them to evolve more rapidly as new insights are gained and new needs emerge from learning communities MOOCs support.

This software perspective provides revealing insights on the emergence of trans-institution, sequenced MOOCs described in Section 5.2, where a course developed at one institution is planned as a prerequisite for a course at another. There are several fundamental ways in which this phenomenon can be mapped to software development. First, it's open, collaborative, and distributed, and thus looks like open-source software development. Second, it begins to reveal distinct possibilities beyond MOOCs-in-the-small (i.e., standalone MOOCs), to MOOCs-in-the-large, which are much larger in scale and composed as intentionally "architected" composition of modular components, eventually encompassing whole fields.

To the extent that MOOCs can rightly be viewed as cyber-social software systems, the perspective yields powerful insights. Many questions follow, including: 
- What is the equivalent of distributed configuration management systems, such as GitHub, for MOOC development across institutional, geographic, and temporal boundaries?

- What coalitions are likely to form to develop large-scale, rapidly evolving mega-MOOCs, e.g., to capture and track the state of knowledge in entire disciplines?

- Do open-source business models work here, as they do for software infrastructure platforms (such as Linux and Apache web server/services) and content management systems (such as Wordpress)?

- What is the equivalent on the continuous testing and integration practices that allow concurrent updates to a single system, while helping to prevent incompatible changes from occurring?

- What is the analog of conceptual integrity in a mega-MOOC developed at a scale that exceeds the capacity of a single instructor? Do issues of film style and sound consistency matter? White balance? Terminology? Interaction design? How do we maintain conceptual integrity as scale increases?

- How do we formulate testable requirements for learning outcomes in the pedagogical domain? How do such "software" requirements trace down into the design, implementation, and execution of the MOOC? How do we as systems engineers gain confidence early in development that a design is sound relative to the stated pedagogical requirements? Production of large-scale MOOCs could cost many millions of dollars; high-end games easily cost $\$ 100$ million dollars.

- Do issues of cost and schedule estimation and project management carry over from traditional software engineering? How do we budget for the production of megaMOOCs?

- What quality attributes (non-function properties) need to be addressed in the design, engineering, implementation, and operation of MOOCs? Examples might include usability, availability, reliability, security, privacy, scalability, stakeholder win-win characteristics, evolvability, affordability, etc.

- What development methods work best for MOOCs? Agile? Waterfall? How do we adopt such methods to this domain? E.g., who is the customer representative in an agile MOOC development project? How do traditional software processes come together with film-like production processes, which are also disciplined, richly developed, and highly structured?

- How do traditional user testing and methodologically-sound curriculum and pedagogical outcomes assessment merge? There are issues of ease of use, but there are ultimately also serious issues of effectiveness. Suppose a MOOC is being used to keep physicians up-to-date with the latest advances in medicine. You'd like to know with high assurance that the learning system is working well.

- How can we model and measure the overall cyber-social system around a MOOC, including the computational and human cognitive states and dynamics of all of the elements, both digital and human - in ways that demonstrably enhance effectiveness in educating people? (cf, cyber-physical.) Can we leverage the full range of increasingly capable sensing technologies: microphones and spoken word, video cameras and facial and affect recognition, etc.?

- What kinds of collaborations and overall systems engineering functions are needed for proper domain and requirements analysis, given that the objectives are a combination of pedagogical (and possibly other e.g., financial in cases where the technology is being used in a corporate training context)?

We expect to see MOOC stakeholders exploring these issues in the next several years.

\subsection{MOOC-Enabled Research for Computing, Learning, and Social Sciences}

Clearly, the rich interconnections among people, content, and tools in the cyber-social system we discussed are ripe for research, both analysis and construction. Given its nature, computer science will be intimately involved in multidisciplinary research involving MOOCs and online education generally [18].

Opportunities for educational data mining abound [18], largely focusing on the search for patterns in student behavioral data from both online and in-class sources. Although educational data mining is still a young field (it predates MOOCs by over five years), MOOCs in particular and online learning generally promise to expand by over an order of magnitude the data from which learning patterns can be mined. Analyses of MOOC data can thus be a boon for the learning sciences.

Much of the data analysis to date with MOOCs is opportunistic, but studies with MOOCs will increasingly aspire to move beyond this opportunistic paradigm in several ways. Foremost among these new directions is that MOOCs will likely host experimental interventions designed to test alternative forms of teaching and learning on student motivation, learning outcomes, and many other performance measures. These interventions will typically be cyber-enabled, though not exclusively.

As noted in Section 4.2, MOOCs are increasingly applied in blended learning environments. The interactions between local and global learning communities are of great interest, subject to opportunistic data mining and proactive experimental intervention. For example, are local students more aware and interested in societal implications of technology (which is a common focus of accrediting bodies, such as ABET) when they are also part of non-local, perhaps national and (usually) global dialog?

Likewise, MOOCs are embedded within rich social and cyber structures. Local and global learning communities can be bounded by design, as well as arising by happenstance. These social themes have been pronounced throughout this paper and elsewhere [18]. Sociologists and behavioral/social scientists of all kinds will learn much from the study of the interactions within these social spaces. YouTube is just one example of the tight coupling between social networks and content repositories, and interactions between individuals as well as changes in the type and amount of content within a MOOCs gravitational field will be subjects of study.

Finally, the deliberative design activities that we have spoken of provide rich research opportunities in computing areas such as human-computer interfaces, software engineering, artificial 
intelligence and machine learning, sensing and robotics to include work in virtual labs and virtually-accessed labs, and other areas.

\section{CONCLUDING REMARKS}

The first generation of MOOCs has largely focused on platforms, methods, and tools for scaling the delivery of high quality "in-thesmall" video-based lecture content presented by one or a small number of faculty, typically from the same institution. In this regard, they have been quite successful, as evidenced by the millions of students who have enrolled in courses offered by the big MOOC content publishers. This section summarizes our views on MOOCs and the future impact they will have on education.

Quality higher education is more than standalone content delivery. It includes tailoring content from multiple sources to meet student needs, mentoring and advising students with respect to life choices, assessing student achievement via substantive exams and labs, and ultimately inspiring students to want to learn. These activities are all labor-and knowledge-intensive, so it's important to consider alternate models for leveraging digital learning, as discussed in Section 4.

Naturally, MOOCs-as-things and MOOCs-in-the-small alone cannot substitute for high quality education. Like books, interactive TV shows, or computer-based training systems discussed in Section 2, they can contribute to raising the quality of our offerings, but learning happens best as an intensely human, social activity. Nor is it just content that students learn, but values, ethics, tolerance, and the ability to coordinate and collaborate. We learn as people, with people, from people. Books and TV shows can help improve the possibilities for learning, but the deepest learning happens in physical and social settings where students and teachers interact. The evolution of MOOCs-asprocesses and MOOCs-in-the-large-coupled with advances in social media tools and virtual/physical meetup groups-will help MOOC faculty and staff communicate with students in ways similar in quality and quantity to those found in large lecture courses at many universities [25].

Life-long and adult, career-oriented and remedial education will increasingly be offered online and take advantage of content developed in MOOCs. Likewise, crowd-sourcing and multi-institutional degrees and competency-based education may become more common. When applied properly, digital learning-exemplified via MOOCs and other dissemination means-can help higher education change for the better, principally by improving the quality, personalization, and effectiveness of education and the student experience.

Standalone MOOCs will increasingly be connected together to form sequenced MOOC specializations. We expect there will soon be a proliferation of MOOC specializations due in part to the growth of trans-institution instructional communities, which are akin to scholarly research communities that frequently span institution boundaries. We also expect that students will press for substitutes to count in place of MOOCs in established sequences, driving us to an open marketplace of courses. Institutions, both academic and corporate, participating in this open marketplace will be challenged in all manner of accreditation, particularly in areas that emphasize competency-based learning, as discussed in Section 5.5. It's possible that these MOOC specializations will eventually compete with majors and minors in established universities, though the current student population in MOOCs is largely disjoint (i.e., 25 years and older) from the population in traditional universities (i.e., largely 18-22 year olds) [25].

Freely available content may not distinguish institutions, but the dedication of educators will. Many aspects of teaching (e.g., interaction, feedback, preparation of labs and exams) are knowledge- and interaction-intensive. Education that can bring together knowledge, skills, and abilities to solve problems in professional fields (such as software engineering) requires small class sizes (real or virtual) and customized learning opportunities. It's worth noting, however, that while digital learning will support flexibility in both time and space, faculty workload might not decrease, based on our experiences teaching online courses. Computers, smart phones, and the Internet have largely blurred the separation of work and non-work times. When digital learning uses all these technologies, the price may be longer working hours for dedicated teachers. Better tools for content creation will also be needed to reduce the time and costs of generating content.

There's a significant risk that decision-makers might view MOOCs as sufficient to substitute for traditional educational methods. Some of these decision makers are driven largely by financial goals, others are driven by antipathy to investments in the public good. The tradeoffs between cost and quality of MOOCs versus traditional education, however, are still poorly understood. Anyone with a stake in higher education should watch their governing boards and administrations closely since some leaders believe in cutting costs by radically reducing the use of traditional faculty, perhaps retaining only a relatively few "star" performers. Big changes can come as (attempted) fait accompli, as evidenced by the chaotic events of summer 2012 at the University of Virginia when the governing board attempted to remove UVA President Sullivan [29].

Content providers and curators must become profitable. As they try, the value propositions for engaging with them may be seen differently. They will face challenges as the technology barriers to entry fall, even to the point that individuals will be able to do a respectable job of producing their own MOOC-like courses. Professors and universities will develop new ways to use these technologies, e.g., to improve traditional student experiences; to generate new revenues (as Georgia Tech is doing with its MOOCbased Professional Masters degree in CS); and in other cases to replace faculty with MOOCs and low-cost instructors.

The quality of education should be as much or more the focus of conversations going forward, as the cost. Our experience is that MOOCs can be used to increase the "bang" as well as reduce the "buck" (or at least stunt its growth). Professors will have to "up their games", get savvy about their own intellectual property, and watch their governing boards and administrations carefully.

The story for students is mixed: good if MOOCs facilitate active learning through flipped classrooms, but with major potential downsides in the longer run if successful educational models are undercut by pedagogically inferior MOOCs. For the public, open access to higher education content and processes is wonderful, but whether it will last is another question.

MOOCs provide a trove of potential riches for the software engineering research and development community. For example, the study of the design and evolution of large-scale, cognitively and socially embedded, content-intensive learning systems, in-the-small and -large, presented many challenges and opportunities for software researchers, as discussed in Section 5.6 


\section{ACKNOWLEDGEMENTS}

The authors appreciate the comments and suggestions for improvement from Kevin Skadron and Jane Cleland-Huang.

\section{REFERENCES}

[1] J. Bailie. and M. Jortberg, “Online Learner Authentication: Verifying the Identity of Online Users,” Journal of Online Learning and Teaching, Vol 5, No 2., 2009.

[2] L. Biemiller, "QuickWire: California Moves Toward Online 2-Year-College Portal,” The Chronicle of Higher Education.

[3] D. Bruff, D. Fisher, K. McEwen, and B. Smith, "Wrapping a MOOC: Student Perceptions of an Experiment In Blended Learning”. Journal of Online Learning and Teaching, Vol 9, No 2. http://jolt.merlot.org/vol9no2/bruff_0613.htm

[4] Capella University, "A New Approach to Learning,” www.capella.edu/online-learning/flexpath/?revkey=206959\&WT.srch=1\&DFAID=1\&gcli $\mathrm{d}=$ CIyU59XOoLsCFVLxOgodzB4A6A.

[5] R. Vedder and M. Denhart, "Why Does College Cost So Much?,” December 2, 2011, CNN.

[6] Fred Connor, "Employers Receptive to Hiring IT job Candidates with MOOC educations," PC World, December 9, 2013,

[7] Department of Homeland Security. National Cybersecurity Workforce Framework: Knowledge, Skills and Abilities, 2013, niccs.us-cert.gov/training/tc/ frame-work/ksas.

[8] U.S. Department of Education, Competency-Based Learning or Personalized Learning, www.ed.gov/oiinews/competency-based-learning-or-personalized-learn-ing.

[9] F. Draganidis, and G. Mentza, "Competency based Management: a Review of Systems and Approaches.” Information Management \&Computer Security. Vol.14, Issue 1. pp. 51-64.

[10] D. H. Fisher, "Warming Up to MOOCs,” Chronicle of Higher Education, November 6, 2012.

[11] A. Fox , "From MOOCs to SPOCs," Communications of the ACM, Vol. 56 No. 12, Pages 38-40, 2103.

[12] P. Hill, “Competency-Based Education: An (Up-dated) Primer for Today’s Online Market

[13] P. Hill, "The Most Thorough Summary of MOOC Completion Rates,” e-Literate, February 26th, 2013.

[14] Gregor Kiczales, “Are MOOCs the New Text-books,” Digital Learning Blog, University of British Columbia, December 4, 2013.

[15] S. Kolowich, "California State U. System Will Expand MOOC Experiment,” The Chronicle of Higher Education, April 2013.

[16] S. Kolowich, “The MOOC 'Revolution' May Not Be as Disruptive as Some Had Imagined,” The Chronicle of Higher Education, August 8, 2013
[17] [MoCCA:14] A. Porter, D.C. Schmidt, and J. White, "Mobile Cloud Computing with Android," Coursera Specialization, www.coursera.org/specialization/mobilecloudcomputing/2.

[18] Workshop on Multidisciplinary Research for Online Education, Washington, DC, February 11-12, 2013: http://www.cra.org/ccc/files/docs/CCC-MROE-Report.pdf

[19] L. Pappano, “The Year of the MOOC,” New York Times, November 2, 2012.

[20] T. Lewin, “After Setbacks, Online Courses Are Rethought,” New York Times, December 10th, 2013.

[21] A.Porter, D.C.Schmidt and J. White, "A Trans-Institution Specialization on Mobile Cloud Computing with Android," Coursera Blog, January 23rd, 2014, www.youtube.com/watch?feature=player_embedded\&v=VYRgO5Q5thM.

[22] J. Rees, “The MOOC Racket,” Slate, July 25th, 2013.

[23] Ry Rivard, “Virtual Lab Experiment,” Inside Higher Ed, May 23, 2013.

[24] J. Rosenberger, “John L. Hennessy on 'The Coming Tsunami in Educational Technology'," Communications of the ACM Blog, July 23, 2012.

[25] D. C. Schmidt and Z. McCormick, Creating and Teaching a MOOC on Pattern-Oriented Software Architecture for Concurrent and Networked Software, Proceedings of the WaveFront Forum at the SPLASH 2013 conference, October 2013, Indianapolis, IN.

[26] D. C. Schmidt, "Pattern-Oriented Software Architectures for Concurrent and Networked Software," www.dre.vanderbilt.edu/ schmidt/Coursera/spring-2013posa.html

[27] UK Government: Department for Business Innovation and Skills, "The Maturing of the MOOC," BIS Research Paper No. 130, September 2013.

[28] UMUC (n.d.). Graduate School Personnel: MS in Information Technology, Information Assurance Specialization, www.umuc.edu/grad/contact.cfm\#mitias.

[29] S. Jaschik, “The E-Mail Trail at UVa,” Inside Higher Ed, June 20, 2012.

[30] S. Carlson, “Competency-Based Education Goes Mainstream in Wisconsin,” The Chronicle of Higher Education, September 30, 2013,

[31] Washington Post, “The Education Issue: UMUC making a name in cybersecurity,” October 31, 2013.

[32] J. Chubb and T. Moe, "Higher Education's Online Revolution,” Wall Street Journal, May 30th, 2012.

[33] J. Wyner, "What Can MOOCs Do for American Higher Education?” Huffington Post, July 2nd, 2013. 
Table 1: Comparing/Contrasting Traditional Residential Education and Online Education Programs

\section{\begin{tabular}{l|l|l} 
Attribute & Traditional Residential Education & Online Education
\end{tabular}}

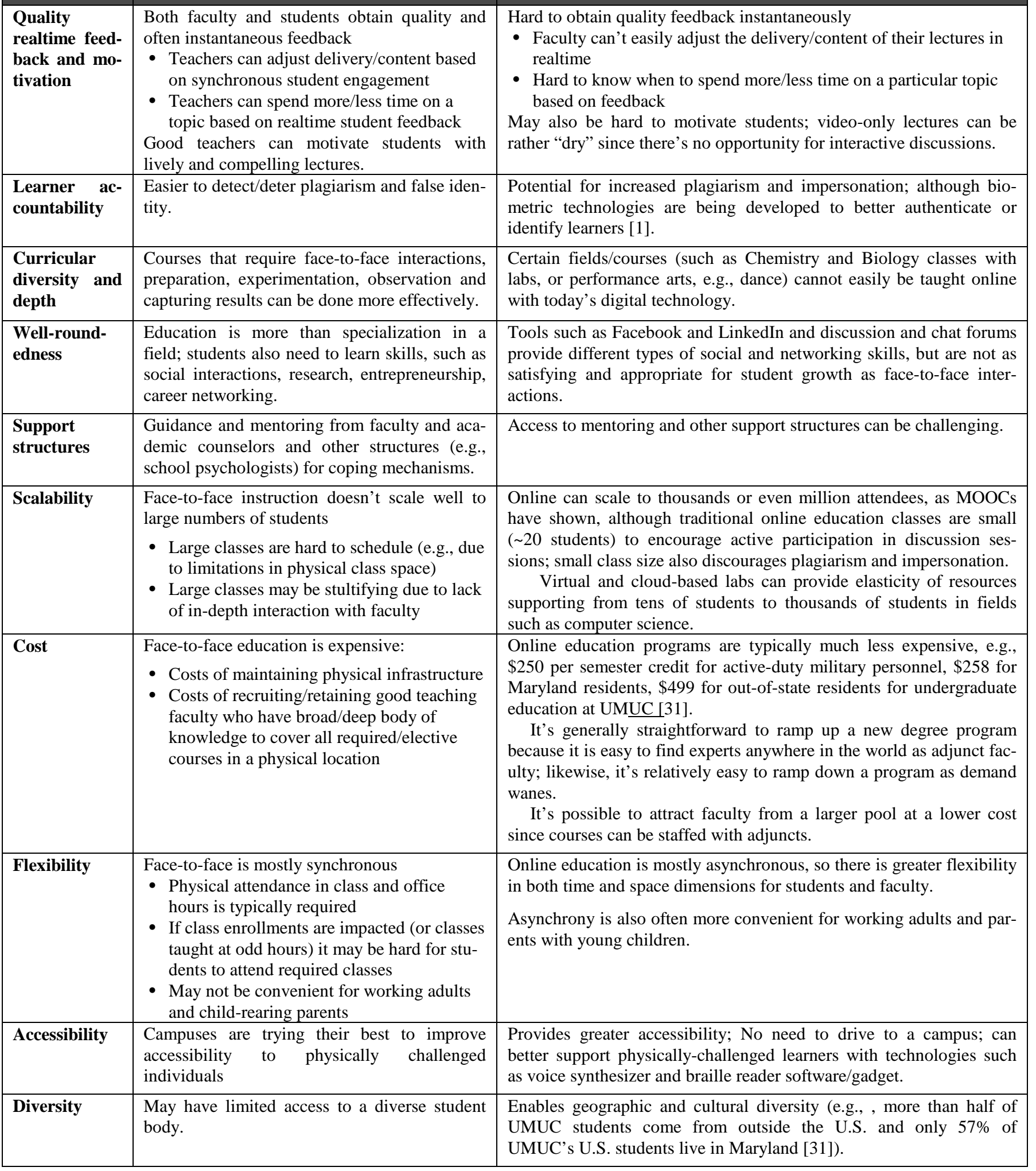

